\title{
Como obter maior eficiência com partículas superficialmente porosas em HPLC
}

\author{
Álvaro José dos Santos Neto \\ Instituto de Química de São Carlos, Universidade de São Paulo - USP, \\ Av. Trabalhador São-carlense, 400, Cep 13560-970, São Carlos, SP, Brasil \\ e-mail: alvarojsn@iqsc.usp.br
}

\section{Resumo}

Os recentes desenvolvimentos da cromatografia líquida têm permitido separações mais eficientes e rápidas. Pode-se citar a recente introdução da UHPLC (Ultra-High Performance Liquid Chromatography), com o uso de colunas preenchidas com partículas porosas menores do que $2 \mu \mathrm{m}$ de diâmetro (sub- $2 \mu \mathrm{m}$ ), bem como o desenvolvimento de colunas com partículas superficialmente porosas sub-3 $\mu \mathrm{m}$ as quais não dependem estritamente de um sistema UHPLC. Apesar de as colunas com partículas superficialmente porosas sub-3 $\mu \mathrm{m}$ apresentarem quase a mesma eficiência daquelas com partículas sub- $2 \mu \mathrm{m}$ totalmente porosas, sob pressões consideravelmente mais baixas, o uso das primeiras em um sistema HPLC "não-otimizado" pode prejudicar parte desse desempenho. Este artigo descreve as implicações do uso de um sistema HPLC convencional sem as possíveis otimizações quando se empregam as colunas com essas fases estacionárias sub- $3 \mu \mathrm{m}$. Ademais, são descritos os procedimentos necessários para otimizar um HPLC convencional, de maneira a se obter um desempenho próximo ao de um UHPLC ao usar essas fases estacionárias sub-3 $\mu \mathrm{m}$.

Palavras-chave

HPLC; UHPLC; partículas superficialmente porosas; volume extracoluna; eficiência, instrumentação.

\section{How to obtain higher efficiency with superficially porous particles in HPLC}

\section{Abstract}

Recent developments in liquid chromatography have enabled faster and more efficient separations. We can cite the recent introduction of UHPLC systems (Ultra-High Performance Liquid Chromatography) with the use of columns packed with sub- $2 \mu \mathrm{m}$ porous particles, as well as the development of columns with sub-3 $\mu \mathrm{m}$ superficially porous particles, which are not strictly restricted to the use of a UHPLC system. Although columns with sub-3 $\mu$ m superficially porous particles exhibit almost the same efficiency of those with sub$2 \mu \mathrm{m}$ totally porous particles, under considerably lower backpressure, the use of a non-optimized HPLC system can hinder part of that performance. This article depicts implications related with the use of a nonoptimized conventional HPLC system when sub-3 $\mu \mathrm{m}$ superficially porous particles columns are employed. Furthermore, procedures for optimizing a conventional HPLC are described in order to obtain performance similar to those of UHPLC systems, when using the above mentioned sub-3 $\mu \mathrm{m}$ stationary phases.

Keywords

HPLC; UHPLC; superficially porous particles; extra-column volume; efficiency; instrumentation. 


\section{Introdução}

Nesta década, os avanços na instrumentação e nos materiais de enchimento para cromatografia líquida têm permitido análises mais rápidas e separações mais eficientes, culminando com o aumento da produtividade dessa técnica e a sua aplicação em problemas mais complexos ${ }^{1}$. Dentre as abordagens apresentadas, pode-se destacar o uso de colunas com suportes monolíticos, o emprego de altas temperaturas, as separações em leitos com partículas sub- $2 \mu \mathrm{m}$ sob ultra-altas pressões e a utilização da tecnologia de colunas preenchidas com partículas superficialmente porosas sub-3 $\mu \mathrm{m}$.

Os suportes monolíticos consistem em um único bloco cilíndrico poroso, o qual está inserido dentro do tubo da coluna cromatográfica. Os materiais monolíticos podem ser orgânicos ou inorgânicos, polimetacritato e poli(estireno-divinilbenzeno), sendo os mais comuns para o primeiro tipo e a sílica para o segundo. Os monólitos à base de sílica são os mais usados em HPLC (do inglês High Performance Liquid Chromatography ou Cromatografia Líquida de Alta Eficiência) ${ }^{1}$. Eles são caracterizados por uma estrutura macroporosa de $2 \mu \mathrm{m}$ e uma mesoporosa de $13 \mathrm{~nm}$, garantindo excelente permeabilidade e eficiências similares àquelas de colunas que contêm partículas porosas de 3 a 3,5 $\mu \mathrm{m}$ de diâmetro. A alta permeabilidade permite $o$ uso de elevadas vazões da fase móvel e garante separações bastante rápidas. Alternativamente, colunas podem ser acopladas em série, elevando o número de pratos da separação. As principais limitações desses materiais referem-se à resistência ao $\mathrm{pH}$ da fase móvel $(2-7,5)$ e a elevadas pressões $(\text { Pmax }=200 \text { bar })^{2}$.

Temperaturas elevadas são viáveis na melhoria do desempenho da HPLC ${ }^{3}$. O emprego dessa estratégia vem sendo chamada
HTLC (do inglês High Temperature Liquid Chromatography ou Cromatografia Líquida a Alta Temperatura). Seus principais efeitos estão relacionados à redução da viscosidade da fase móvel, a qual permite mais alta difusão dos analitos e leva a maior eficiência do processo de transferência de massa. Adicionalmente, também se observa uma redução na pressão da coluna e, em associação com a característica anterior, permite análises mais rápidas por meio do aumento da vazão da fase móvel. As modificações nas características físico-químicas dos solventes e solutos, decorrentes das altas temperaturas, implicam a necessidade de adaptações dos métodos sob essas condições. Por exemplo, variações na tensão superficial e constante dielétrica da água podem aumentar a sua força de eluição relativa à fase estacionária (requerendo menor percentual de solvente orgânico na fase móvel); alterações do pKa de solutos básicos também podem modificar as interações secundárias dentro da coluna e/ou a seletividade para um certo $\mathrm{pH}$ da fase móvel ${ }^{4}$. Essas modificações de características físico-químicas, por um lado, podem ser exploradas como forma de melhorar a seletividade do método; por outro lado, elas implicam ajustes significativos ao se fazer a transferência de um método previamente desenvolvido para um equivalente sob elevadas temperaturas. Outras limitações são a necessidade de instrumentação capaz de controlar adequadamente a temperatura da fase móvel, a eventual degradação dos compostos e a instabilidade térmica de algumas fases estacionárias.

Há tempos está bem estabelecido na teoria da cromatografia que o uso de colunas com partículas menores resulta em maiores eficiências e permite o uso de mais altas velocidades ótimas de análise. Por outro lado, quanto menor o tamanho da partícula, mais altas pressões se fazem 
necessárias para garantir a mesma vazão da fase móvel. A partir de 2004, foram comercialmente disponibilizadas colunas com partículas sub-2 $\mu \mathrm{m}$, bem como instrumentação capaz de alimentar essas colunas com pressões superiores a 1000 bar. O termo UHPLC (do inglês UltraHigh Performance Liquid Chromatography ou Cromatografia Líquida de Ultraeficiência) tem sido recentemente utilizado para descrever separações que ocorrem com essas colunas sob pressões que superam 400 bar $^{5}$. Na prática, separações em UHPLC podem ser realizadas em curtíssimos tempos de análise, com o mesmo poder de resolução de análises convencionais. Além disso, atualmente existem diversas colunas disponíveis (mais de dez fabricantes) para esse tipo de separação, tornando bastante viável a transferência de métodos de um HPLC convencional para um UHPLC. As principais limitações à ampla utilização da UHPLC ainda são instrumentais, uma vez que se fazem necessários equipamentos especiais com bombas e sistemas de injeção capazes de suportar altíssimas pressões e detectores com elevadas taxas de aquisição de dados devido aos rápidos ciclos de análise e reduzidos volumes a serem percorridos pela fase móvel.

As duas abordagens apresentadas acima, HTLC e UHPLC, podem ser utilizadas em conjunto, expandindo ainda mais o desempenho de um sistema ${ }^{6}$. Essa estratégia vem sendo chamada HT-UHPLC e tem a capacidade de atingir o máximo de produtividade (alta eficiência em um mínimo de tempo) em HPLC ${ }^{1}$.

A tecnologia mais recentemente introduzida como estratégia para melhoria da eficiência em HPLC utiliza partículas superficialmente porosas sub-3 $\mu \mathrm{m}$ (do inglês superficially porous particles $)^{7}$. Em inglês essa tecnologia também tem sido chamada de Fused-Core, Core-Shell e PorousShell, entre outros nomes, e deriva das partículas peliculares desenvolvidas no passado ${ }^{8}$. Neste texto, essa tecnologia será tratada como "SPP sub-3 $\mu \mathrm{m}$ ". As "SPP" atuais têm tamanho típico de 2,6 ou 2,7 $\mu \mathrm{m}$ de diâmetro e são constituídas de um núcleo sólido não poroso (core), portanto impermeável, que é externamente revestido por uma camada porosa (shell) típica das partículas convencionais de HPLC (Figura 1). Em contraste com as partículas peliculares do passado, as quais consistiam em partículas relativamente grandes com uma fina camada porosa superficial, as partículas atuais geralmente têm ao menos $60 \%$ do seu volume total correspondente à camada porosa. A Figura 2 ilustra o desempenho comparativo entre uma coluna convencional e uma coluna "SPP sub-3 $\mu \mathrm{m}$ " moderna aplicadas à mesma amostra, enquanto a Figura 3 compara-a com uma coluna "sub-2 $\mu \mathrm{m}$ ". Essas novas colunas exibem eficiências próximas àquelas das colunas de UHPLC, porém necessitam aproximadamente da metade da pressão típica de tais sistemas².

Todas as abordagens apresentadas acima conferem um ganho significativo de produtividade e eficiência/capacidade de picos em relação à HPLC convencional (com partículas porosas de 3 a $5 \mu \mathrm{m}$ de diâmetro) ${ }^{1}$. Certamente HT-UHPLC tem o maior destaque nesses aspectos, seguida da UHPLC. A tecnologia "SPP sub-3 $\mu \mathrm{m}$ ” e o emprego isolado de HTLC também garantem excelentes desempenhos e, por último, mas ainda em grande destaque comparativo à HPLC convencional, apresenta-se a tecnologia das colunas monolíticas ${ }^{1}$. Diante dos resultados mostrados na literatura, pode-se inferir que o uso da tecnologia "SPP sub-3 $\mu \mathrm{m}$ " em condições de elevadas pressões (UHPLC) e altas temperaturas (HTLC) deverá ter a capacidade, no futuro, de atingir níveis de desempenho sem precedentes. Atualmente alguns estudos encontram-se em desenvolvimento nesse sentido, e colunas com partículas “SPP” com 1,7 $\mu$ m já são comercialmente disponíveis (Figura 1b). O uso 
Tamanho total da partícula $=2,7 \mathrm{~mm}$

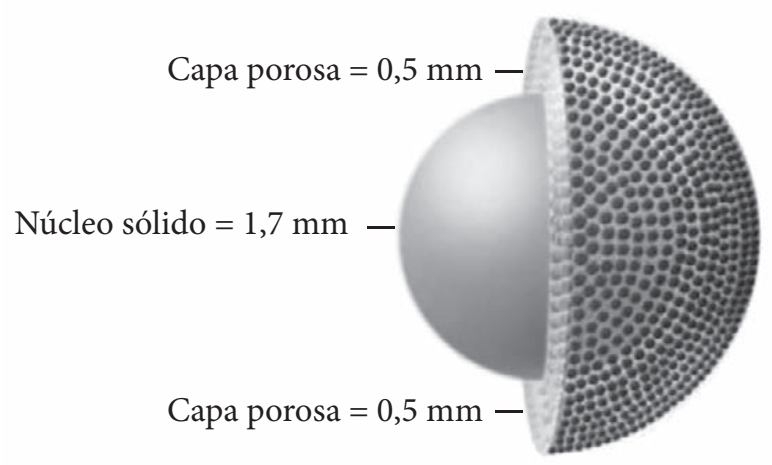

(a)

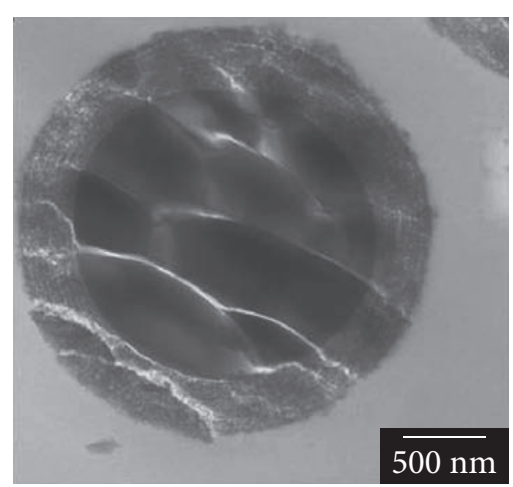

(i)

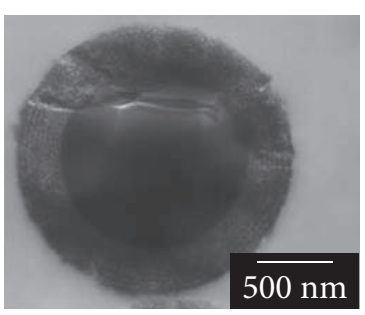

(ii)

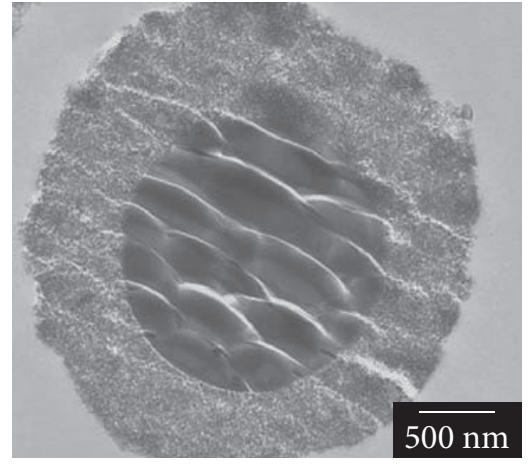

(iii)

(b)

Figura 1 a) Esquema de uma partícula superficialmente porosa. O núcleo central ("core") ilustrado em amarelo é impermeável, sendo revestido externamente por uma camada porosa ("shell"), a qual é parcialmente representada na figura. Reproduzida com a permissão de Agilent Technologies. b) Imagens de um corte de partículas superficialmente porosas obtidas por microscopia eletrônica de transmissão (i) partícula com 2,6 $\mu \mathrm{m}$ de diâmetro da marca Kinetex, (ii) partícula com 1,7 $\mu \mathrm{m}$ de diâmetro da marca Kinetex, e (iii) partícula de 2,7 $\mu \mathrm{m}$ de diâmetro da marca Halo. Republicado a partir da referência 9, com permissão da Elsevier.

de altas pressões foi demonstrado ${ }^{6,11}$, e empresas comercializam essas colunas para trabalhar até pressões de 600 bar e, em alguns casos, 1000 bar. Por outro lado, alguns trabalhos demonstraram o uso de temperaturas na faixa de 50 a $60{ }^{\circ} \mathrm{C}$ com essas colunas ${ }^{6,2}$, e esforços devem estar sendo empreendidos pelos fabricantes para aumentar a estabilidade térmica desses materiais.
Como pôde ser observado acima, cada uma das tecnologias apresenta suas vantagens inerentes e algumas limitações. Todavia, do ponto de vista instrumental, as maiores limitações recaem sobre a UHPLC, uma vez que um equipamento especialmente desenvolvido para usar altas pressões e para detectar os picos muito estreitos resultantes deve ser utilizado. O uso da HTLC também requer um controle rigoroso da tem- 


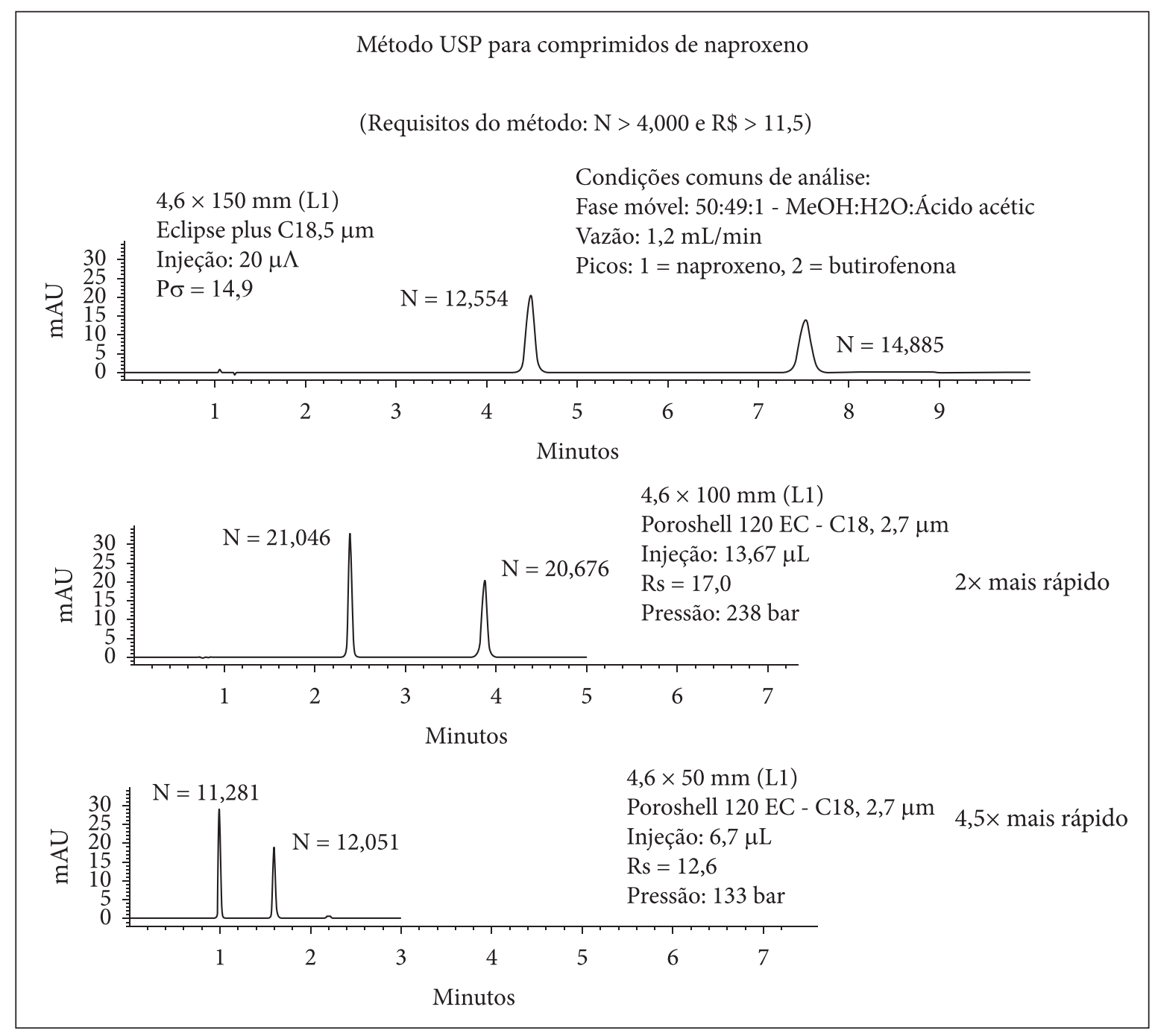

Figura 2 Cromatogramas comparativos entre uma coluna de HPLC convencional (150 × 4,6 mm) com partículas totalmente porosas de $5 \mu \mathrm{m}$ e colunas modernas de $100 \times 4,6 \mathrm{~mm}$ e $50 \times 4,6 \mathrm{~mm}$ preenchidas com partículas superficialmente porosas de $2,7 \mu \mathrm{m}$ de diâmetro. Todas as colunas sendo utilizadas em condições compatíveis com um equipamento HPLC convencional. Reproduzida com a permissão de Agilent Technologies.

peratura da fase móvel, isso geralmente exige dispositivos especiais em um HPLC e colunas com um diâmetro interno reduzido. Restam, dessa forma, as tecnologias "SPP sub-3 $\mu$ m" e de suportes monolíticos como sendo as menos exigentes do ponto de vista de uma instrumentação exclusivamente dedicada. Dessas duas últimas, a "SPP sub-3 $\mu \mathrm{m}$ ", apesar de mais recente, tem indicado que será mais aceita pelos usuários da cromatografia. Por um lado, ela apresenta um desempenho superior e menos limitações quanto à pressão e ao $\mathrm{pH}$ de uso ${ }^{1}$; por outro, ao menos quatro fabricantes encontram-se no mercado, em contrapartida a dois fabricantes de colunas monolíticas à base de sílica. A Figura 4 compara as eficiências das colunas mencionadas anteriormente com a de uma coluna convencional de $3 \mu \mathrm{m}$. Observe que todas as colunas modernas possuem o lado direito de suas curvas (Termo C de van Deemter) com menor inclinação do que 

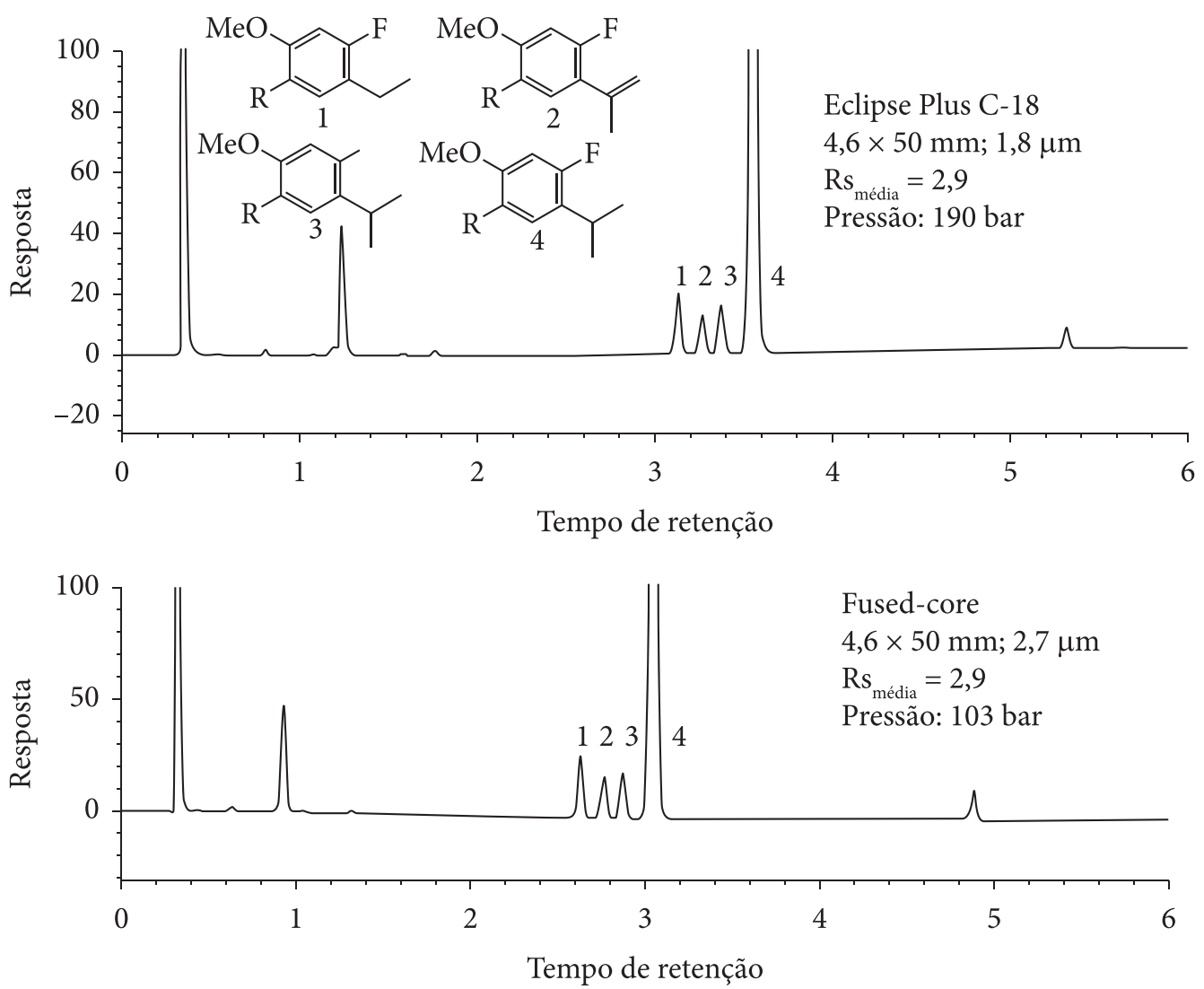

Figura 3 Cromatogramas de um composto intermediário de um fármaco e suas impurezas. Análise comparativa usando colunas de $50 \times 4,6 \mathrm{~mm}$ preenchidas com partículas totalmente porosas de 1,8 $\mu$ m e com partículas superficialmente porosas de $2,7 \mu \mathrm{m}$. Republicado a partir da referência 10, com permissão da Elsevier.

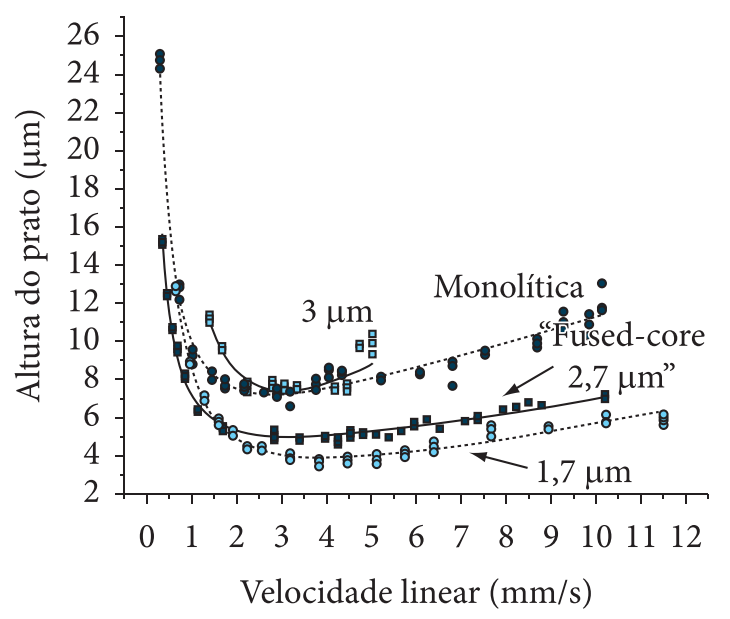

Figura 4 Gráficos de van Deemter para o etilbenzeno obtidos a partir de quatro diferentes colunas (conforme indicado). Fase móvel $\mathrm{ACN}: \mathrm{H}_{2} \mathrm{O}, 70: 30\left({\left.\mathrm{v} \cdot \mathrm{v}^{-1}\right) \text { e volume }}\right.$ de injeção de 0,6 $\mu \mathrm{L}$. Reproduzido com permissão a partir da referência 2; direitos autorais de Wiley-VCH Verlag GmbH \& Co. KGaA. a respectiva porção da curva da coluna convencional, demonstrando que análises mais rápidas podem ser obtidas sem um grande comprometimento da eficiência cromatográfica, mesmo com vazões significativamente mais altas que a velocidade linear ótima $\left(\mu_{\text {opt }}\right)$.

Em vista da situação apresentada acima, a tecnologia "SPP sub-3 $\mu \mathrm{m}$ " mostra-se como uma abordagem capaz de ser utilizada em equipamentos com uma configuração mais próxima àquela dos HPLC convencionais. Nesse ponto, é importantíssimo salientar que a maior parte das empresas/representantes dessa tecnologia sabe indicar as exigências instrumentais que tais colunas apresentam. Contudo, inadvertidamente, a alguns usuários pode ser passada a impressão 
de que tais colunas são capazes de oferecer o seu máximo de desempenho em um HPLC convencional "não-otimizado". É óbvio que a substituição de uma coluna convencional com diâmetro de partículas da ordem de 3 a $5 \mu$ m por uma "SPP sub-3 $\mu$ m” levará a uma maior eficiência, porém isso não significa que todo o potencial dessas colunas estará sendo explorado.

Um HPLC convencional, quanto às pressões máximas permitidas, tem a capacidade de atender a demanda de uma coluna "SPP sub- $3 \mu \mathrm{m}$ " de maneira bastante razoável. Contudo, os efeitos do "volume extracoluna" (ECV, do inglês extra-column volume) e algumas configurações da aquisição e tratamento do sinal do detector podem prejudicar significativamente o desempenho geral dessas separações. De fato, em artigos anteriores dessa seção, já foi chamada a atenção aos problemas ocasionados pelo excesso de ECV na HPLC ${ }^{13,14}$. Como as separações em "SPP sub-3 $\mu \mathrm{m}$ " ocorrem em velocidades mais altas, e essas colunas apresentam excelente eficiência, picos bastante estreitos são obtidos, os quais correspondem a bandas cromatográficas com volumes bastante reduzidos. Dessa forma, sistemas HPLC com configurações "não-otimizadas" podem apresentar um excesso de ECV tão comprometedor ao ponto de prejudicar drasticamente a eficiência intrínseca de uma coluna "SPP sub-3 $\mu \mathrm{m}$ ". Atualmente, além dos sistemas UHPLC fabricados por diversas empresas, encontram-se também sistemas classificados como sendo de "cromatografia rápida", algumas denominações usuais em inglês utilizadas por essas empresas são Rapid Resolution Liquid Chromatography, UltraFast Liquid Chromatography, e Rapid Separation Liquid Chromatography, entre outras. Esses sistemas, em geral, são configurações "de fábrica" de equipamentos mais próximos aos HPLC convencionais, porém com especial atenção à redução dos desnecessários ECV, à otimização da fluídica do sistema e à utilização de detectores rápidos o suficiente para registrar picos bastante estreitos.

Este artigo apresenta as principais implicações que um sistema HPLC "não-otimizado" tem sobre as separações obtidas com colunas de alta eficiência do tipo "SPP sub-3 $\mu \mathrm{m}$ ". Adicionalmente, modificações passíveis de serem executadas nos sistemas HPLC convencionais serão apresentadas e discutidas, de modo que os usuários interessados possam gradativamente tornar os seus sistemas "relativamente ultrapassados" bastante competitivos frente às novas tecnologias UHPLC. Em outras palavras, este artigo trata de "como evitar que um sistema HPLC convencional acabe com boa parte da eficiência que uma coluna cromatográfica moderna pode oferecer".

\section{O papel dos efeitos extracoluna sobre a eficiência cromatográfica}

A eficiência total exibida em uma separação cromatográfica decorre da própria coluna cromatográfica e de aspectos extracoluna. Os fatores que afetam a eficiência intrínseca da coluna são bem conhecidos e geralmente relacionados com os termos A, B e C da equação de van Deemter (ou de equações derivadas dela), os quais são: efeito dos caminhos múltiplos, difusão longitudinal do analito e resistência à transferência de massa do analito na fase móvel e na fase estacionária, respectivamente. As colunas modernas têm a sua dinâmica de funcionamento otimizada justamente para minimizar o efeito que cada um dos termos acima representa no alargamento que uma banda cromatográfica experimenta no interior da coluna. Adicionalmente aos fatores acima, contribuições externas à coluna também afetam a eficiência apresentada no cromatograma. Esses efeitos são os denominados efei- 
tos extracoluna e, em boa parte, são devidos ao ECV mencionado anteriormente. Esses efeitos são decorrentes de todas as regiões do cromatógrafo, a partir do sistema de injeção até o sistema de detecção (excetuando-se a coluna), e contribuem para o alargamento do pico cromatográfico. Do ponto de vista estatístico, a largura do pico cromatográfico é definida por meio de sua variância $\left(\sigma^{2}\right)$, de maneira que o alargamento total da banda cromatográfica registrada no cromatograma pode ser calculado pela equação abaixo:

$$
\sigma_{\text {total }}^{2}=\sigma_{\text {coluna }}^{2}+\sigma_{\text {extracoluna }}^{2}
$$

em que $\sigma_{\text {total }}^{2}$ é a variância total do pico apresentado no cromatograma; $\sigma_{\text {coluna }}^{2}$ a variância atribuída à contribuição intrínseca da coluna e $\sigma_{\text {extracoluna }}^{2}$ a variância relativa aos efeitos extracoluna. Estatisticamente, quando se deseja somar fontes distintas de dispersão de resultados, elas devem ser somadas por meio de suas variâncias e não a partir dos seus valores de desvio-padrão $(\sigma)$.
Os efeitos extracoluna, por sua vez, podem ser divididos em diversas contribuições particulares, as quais são equacionadas abaixo:

$$
\begin{gathered}
\sigma_{\text {extracoluna }}^{2}=\sigma_{\text {injetor }}^{2}+\sigma_{\text {detector }}^{2}+ \\
\sigma_{\text {tubos e conexões }}^{2}+\sigma_{\text {eventos de aquisição dos dados }}^{2}
\end{gathered}
$$

em que cada variância representa a dispersão causada pelas respectivas partes ou eventos envolvidos na análise cromatográfica.

A Figura 5 ilustra cada um dos pontos de contribuição para o alargamento da banda cromatográfica em um sistema HPLC.

O sistema de injeção contribui com o próprio volume de amostra introduzido no sistema. Adicionalmente, dependendo do tipo de configuração do injetor utilizado, outros fatores somam-se ao volume da amostra, por exemplo: volume interno da válvula de injeção, volume não preenchido da alça de amostragem (no caso de inversão equivocada entre os pórticos de conexão da coluna e da bomba), volume do dispositivo de assentamento/encaixe da agulha de injeção e

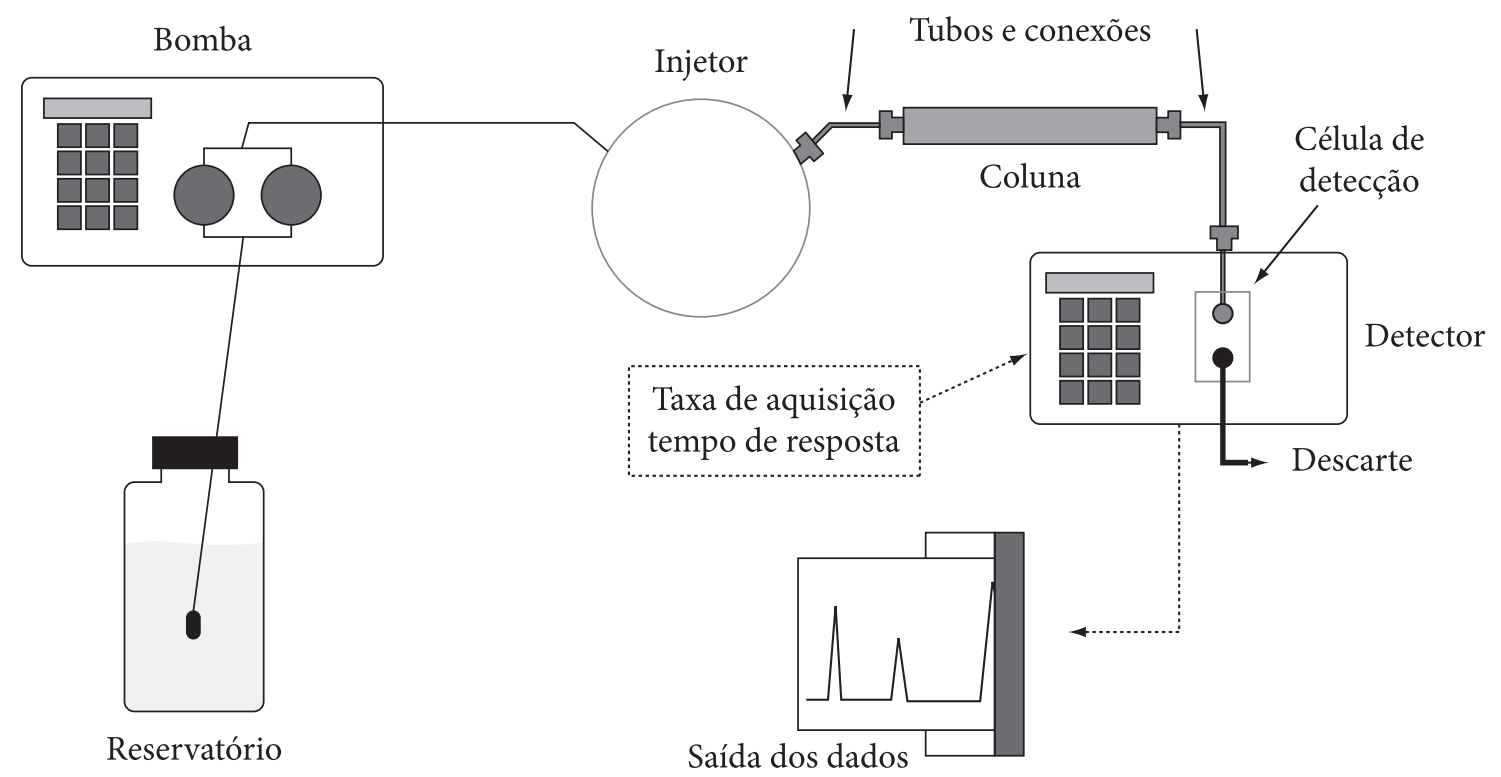

Figura 5 Esquema de um sistema HPLC. As áreas em vermelho representam os dispositivos ou fatores que causam o alargamento extracoluna da banda cromatográfica, em laranja está representada a coluna, principal responsável pelo alargamento dos picos em um sistema otimizado. 
conexão deste com a válvula injetora. Além dos próprios volumes, a dinâmica fluídica do dispositivo também influencia para um maior ou menor alargamento da banda. Idealmente a geometria de válvulas, tubos e conexões é projetada de maneira a minimizar o processo de difusão causado pela transferência de massa em seu interior.

A princípio, duas modalidades de introdução da amostra têm sido empregadas em HPLC: “injeção" manual e por meio de amostrador automático. Na primeira, uma alça de amostragem instalada em uma válvula é preenchida, transferindo-se para o seu interior a amostra líquida presente no interior de uma seringa. A seguir, a válvula é acionada manualmente ou por meio de um dispositivo pneumático ou eletro-mecânico, inserindo a alça e, consequentemente, o seu conteúdo no caminho percorrido pela fase móvel que vem impulsionada pela bomba em direção à coluna cromatográfica. A injeção da amostra na alça pode ser feita de maneira a preenchê-la parcialmente ou totalmente. Todavia, por causa da dinâmica do fluido no interior das tubulações, algumas limitações devem ser mencionadas. Quando se promove a injeção do líquido, as porções adjacentes à parede do tubo movem-se mais lentamente do que as porções centrais do fluido. Dessa forma, observando-se longitudinalmente, ocorre a formação de um perfil parabólico, em que a região central chega a ter o dobro da velocidade de preenchimento da região contígua à parede do tubo. Esse perfil faz com que uma parte da amostra comece a deixar o seguimento do tubo compreendido pela alça de amostragem antes que a alça esteja completamente preenchida. De maneira prática, para a obtenção de uma boa precisão do procedimento de amostragem, recomenda-se que a alça seja parcialmente preenchida até $50 \%$ de seu volume nominal, ou que então seja completamente preenchida usando um excesso de amostra ( $\geq 200 \%$ do volume nominal da alça). Por causa da dificuldade em se medir manualmente com uma seringa, para um volume bastante preciso a ser introduzido no interior da alça de amostragem, a forma mais recomendada e popularizada de injeção manual é aquela com alça totalmente preenchida. Para se ter certa versatilidade em relação aos volumes de injeção, dependendo do fabricante e modelo de válvula, podem ser encontradas alças que variam entre 1 ou $2 \mu \mathrm{L}$, até mais de $1 \mathrm{~mL}$, bem como algumas alças presentes internamente nos rotores da válvulas, as quais podem chegar a menos que $60 \mathrm{~nL}$.

No caso dos amostradores automáticos, existem ao menos três formas básicas e distintas para introdução da amostra. Todas se baseiam na utilização de, ao menos, uma válvula e uma bomba/ seringa mecanizada para promover o deslocamento de um volume da amostra. A forma mais simples e pouco utilizada na atualidade baseia-se na aspiração da amostra para o interior da alça de amostragem, a qual, totalmente preenchida, posteriormente é deslocada para o caminho da fase móvel em direção à coluna; em inglês, esse modo de injeção é chamado pull to fill. Outro modo, o qual é bastante encontrado nos sistemas atuais, é chamado em inglês de push to fill e assemelha-se ao preenchimento manual da alça de amostragem, exceto pelo fato de que a amostra é aspirada para o interior da agulha e tubulação de amostragem e, em seguida, transferida para o interior da alça em um processo mecanizado. Devido à maior precisão executada nas medidas de volume pelo sistema mecanizado, essa técnica pode ser utilizada tanto no modo de preenchimento parcial quanto no total da alça, obtendo-se, em ambas, uma adequada precisão (desde que respeitados os percentuais de preenchimento citados anteriormente). $\mathrm{O}$ terceiro modo de amostragem, o qual vem sendo bastante utilizado pelos equipamentos comercializados atualmente, é chamado 
em inglês de integral-loop. Nesse caso, a agulha de aspiração que é inserida no frasco da amostra tem seu volume interno integrado à alça de amostragem. Dessa forma, depois de aspirado um volume exato da amostra, a agulha é selada em uma das portas da válvula de injeção, de maneira a resistir às altas pressões. Assim, quando a válvula é girada, todo o conteúdo aspirado é levado pela fase móvel à coluna.

Cada uma das formas de inserção tem suas vantagens e desvantagens sob diversos aspectos. Uma revisão mais abrangente sobre essas formas de introdução da amostra pode ser encontrada nas referências de 15 a 17. A utilização de uma alça de volume suficientemente pequeno e totalmente preenchido, quer seja no modo manual quer no automático, fornece a menor dispersão da amostra dentro do volume de amostragem, uma vez que todo o espaço disponível estará homogeneamente preenchido pela solução. Por outro lado, essa é a modalidade que permite menor flexibilidade, pois a alça de amostragem deve ser trocada para ocorrer variação do volume amostrado. Na prática, os amostradores automáticos que trabalham com preenchimento parcial (tanto no modo push to fill quanto no integral-loop), apesar de intrinsecamente contribuírem para uma dispersão um pouco maior da banda cromatográfica, podem, em muitos casos, promover injeções com precisões e volumes compatíveis com colunas modernas de HPLC/ UHPLC. Recomenda-se verificar nas especificações do amostrador automático disponível qual ou quais tipos de injeção são possíveis, qual o volume mínimo recomendado pelo fabricante e qual a precisão conseguida com ele. $\mathrm{Na}$ dúvida sobre se os pequenos volumes de injeção serão reprodutíveis, a injeção repetida (de 5 a 10 vezes) de uma solução padrão fornecerá estimativa do coeficiente de variação das injeções, permitindo avaliar a adequação à finalidade do método.
Outra fonte de dispersão é atribuída ao volume interno dos tubos e conexões que são utilizados para conectar a coluna cromatográfica ao injetor e ao detector. Eventualmente, deve-se somar a esse volume a contribuição de filtros de linha (in-line filters) ou pré-colunas acoplados preventivamente à coluna analítica, bem como dispositivos para aquecimento da fase móvel que é direcionada à coluna.

O sistema de detecção contribui de duas maneiras para o alargamento dos picos cromatográficos. O volume interno da célula de detecção em fluxo contribui diretamente para o alargamento da banda. Nesse dispositivo, deseja-se (no caso de detectores UV-Vis) o mais longo caminho óptico possível para o feixe de radiação eletromagnética, sem que ele contribua em excesso com o volume extracoluna. Além do volume intrínseco do detector, os eventos de aquisição e tratamento eletrônico-computacional dos dados também podem contribuir para o alargamento do pico cromatográfico. Os dois parâmetros relacionados com essa contribuição são a taxa/ frequência de aquisição de dados do detector e o seu tempo de resposta. Esses parâmetros são ajustados de maneira a se obter um número mínimo de pontos de aquisição ao longo do pico cromatográfico e a se atenuar suficientemente o ruído da linha de base sem alargar os picos. Idealmente, a taxa de aquisição deve ser regulada para garantir ao menos 20 pontos de aquisição ao longo do pico mais estreito de interesse no cromatograma. O tempo de resposta do detector (response time, ou digital filter response são alguns dos termos em inglês) está relacionado com a constante de tempo (time constant) e é o responsável por eletronicamente e/ou computacionalmente atenuar o ruído de alta frequência do detector. Quanto mais longo for o tempo de resposta, menor o ruído registrado na linha de base; todavia, um tempo demasiadamente longo 
afeta o pico cromatográfico adquirido, tornando-o mais baixo e largo em relação ao aspecto real apresentado pela banda cromatográfica. A Figura 6 ilustra o efeito desses parâmetros de detecção. Observe que os picos mais estreitos (em unidades de tempo), adquiridos sob uma vazão de $1,0 \mathrm{~mL} / \mathrm{min}$, sofrem mais com taxas de aquisição baixas, constantes e longas de tempo.

\section{Quando os fatores extracoluna começam a prejudicar significativamente a eficiência da coluna}

Como explicitado acima, a eficiência obtida em uma separação é fruto dos processos de alar-

$0,1 \mathrm{~mL} / \mathrm{min}$
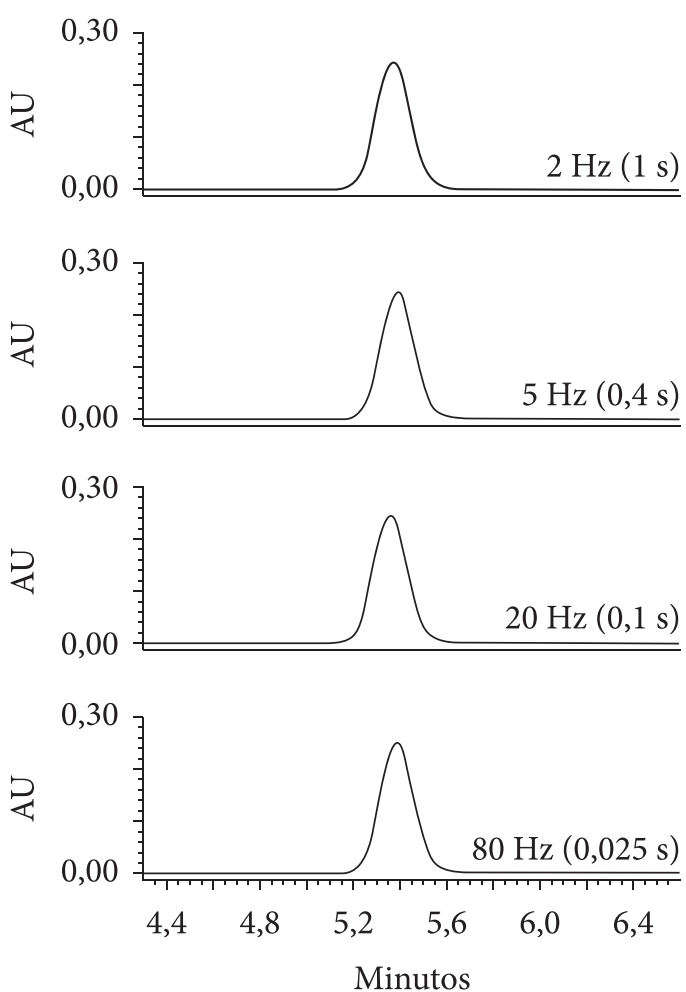

gamento da banda cromatográfica ocorridos dentro da coluna e também fora dela. Todavia, em um sistema idealmente configurado, espera-se que a contribuição dos processos ocorridos fora da coluna seja desprezível.

A contribuição dos fatores intra e extracoluna na eficiência será ilustrada por uma separação em coluna de $150 \times 4,6 \mathrm{~mm}, 5 \mu \mathrm{m}$. Será considerada uma coluna com porosidade total igual a $0,6(60 \%$ do volume do tubo ocupado pela fase móvel), um analito com fator de retenção igual a quatro $(k=4)$, uma vazão de $1,0 \mathrm{~mL} / \mathrm{min}$ e altura do prato da coluna $(H)$ igual a $11,5 \mu \mathrm{m}$. Usando fórmulas básicas de cromatografia, pode-se calcular uma eficiência $(N)$ intrínseca à coluna igual a 13.044 pratos, $t_{0}$ e $t_{\mathrm{R}}$ do analito iguais a 1,5 e 7,5 minutos, equivalentes a $V_{0}$ e $V_{\mathrm{R}}$ de 1,5 e $7,5 \mathrm{~mL}$.

$1,0 \mathrm{~mL} / \mathrm{min}$
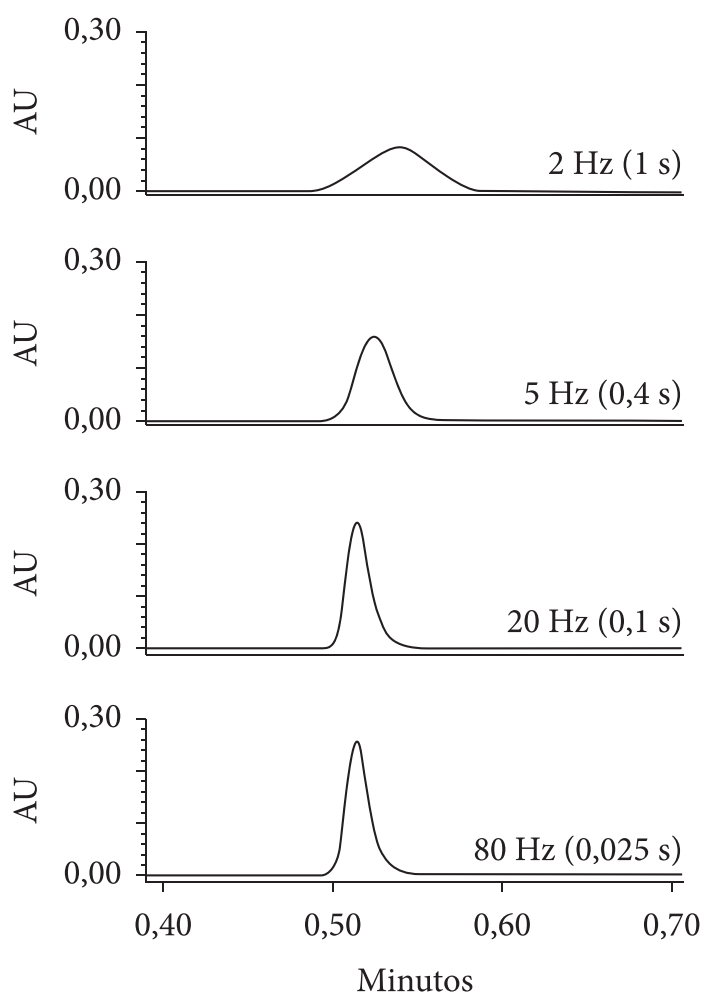

Figura 6 Influência das condições de detecção sobre o alargamento dos picos. Os números em parênteses, ao lado direito da taxa de aquisição, são a constante de tempo do filtro de ruído do detector. O composto testado foi o acenafteno $\left(0,2 \mathrm{mg} \cdot \mathrm{mL}^{-1}\right)$ com fator de retenção igual a 3,6. Republicado a partir da referência 18, com permissão da Elsevier. 
Usando $N=\left(\frac{V_{R}}{\sigma}\right)^{2}$, tem-se que $\sigma_{\text {coluna }}^{2}$ é $4.313 \mu \mathrm{L}^{2}$. Considerando-se como aceitável uma perda de $10 \%$ na eficiência intrínseca da coluna, causada pelos efeitos extracoluna, isso significa que se pode aceitar uma $\sigma_{\text {extracoluna }}^{2}$ de aproximadamente $480 \mu \mathrm{L}^{2}$. Usualmente, um sistema HPLC convencional moderno apresenta uma $\sigma_{\text {extracoluna }}^{2}$ entre 40 e $60 \mu \mathrm{L}^{2}$, contudo um sistema mal configurado pode apresentar variância bastante superior a $100 \mu \mathrm{L}^{2}$. Como pode ser observado pelos valores acima, usando uma coluna convencional, as fontes típicas de dispersão de um HPLC não são capazes de afetar significativamente a eficiência de uma coluna.

Por outro lado, considerando-se uma coluna moderna com $50 \times 4,6 \mathrm{~mm}$, "SPP 2,6 $\mu \mathrm{m}$ " exibindo $H=3 \mu \mathrm{m}$, porosidade total de 0,6 e um analito pouco retido com $k=1$ sob vazão de $1,0 \mathrm{~mL} / \mathrm{min}$, tem-se os seguintes resultados: $N=16.667, V R=1,0 \mathrm{~mL}$ e $\sigma_{\text {coluna }}^{2}$ de aproximadamente $60 \mu \mathrm{L}^{2}$. Nesse caso, um sistema HPLC convencional com $\sigma_{\text {extracoluna }}^{2}$ de aproximadamente $60 \mu \mathrm{L}^{2}$, implicaria em uma redução de $50 \%$ na eficiência final da separação ( $N$ de aproximadamente 8.300).

Em contrapartida, a $\sigma_{\text {extracoluna }}^{2}$ para um sistema UHPLC varia entre 4 e $10 \mu \mathrm{L}^{2}$ geralmente. Considerando um valor típico de $6 \mu \mathrm{L}^{2}$, ele equivaleria a apenas $9 \%$ de prejuízo em relação à eficiência da coluna "SPP 2,6 $\mu \mathrm{m}$ ” ilustrada no parágrafo anterior.

Os exemplos apresentados permitem uma visualização clara do quão significante pode ser o efeito extracoluna em uma separação com colunas modernas, enquanto o mesmo sistema cromatográfico praticamente não afetaria a eficiência com colunas convencionais. Pelos cálculos apresentados, é bastante óbvio que, quanto mais eficiente for a coluna e menos retido o analito, menor será a variância do pico e, consequente- mente, mais significativo o efeito da variância extracoluna. Como os equipamentos UHPLC são configurados para colunas bastante eficientes, eles não comprometem o seu desempenho. Todavia, um sistema HPLC convencional pode afetar bastante o desempenho dessas colunas modernas, caso seu ECV seja excessivo. Como regra geral, deve-se manter o ECV do sistema com um volume máximo de $2 \sigma$ coluna (calculado pela eficiência da coluna, seu volume morto e o fator de retenção do composto de interesse). Por exemplo, uma coluna com a $\sigma_{\text {coluna }}^{2}$ igual a $60 \mu \mathrm{L}^{2}$ manteria $90 \%$ de seu desempenho se utilizada em um sistema com ECV total de até aproximadamente $15,5 \mu \mathrm{L}$.

Outro aspecto importante que deve ser considerado é o diâmetro interno da coluna. Se as mesmas condições apresentadas acima forem consideradas para uma coluna "SPP 2,6 $\mu \mathrm{m}$ ” com apenas 2,1 mm de diâmetro interno, picos com variância de apenas $2,6 \mu \mathrm{L}^{2}$ podem ser esperados. Nesse caso, mesmo uma otimização detalhada de um sistema HPLC convencional provavelmente não será suficiente e até um equipamento UHPLC poderá sofrer por excesso de efeitos extracoluna.

Existem diversas formas para estimar o ECV do sistema cromatográfico ou se calcular diretamente a dispersão total extracoluna da banda (efeito da dispersão causada pelo ECV e outros fatores extracoluna), a qual está relacionada com a $\sigma_{\text {extracoluna. Um dos métodos para estimar }}^{2}$ o ECV consiste em se somarem todos os volumes do sistema a partir do injetor; por exemplo, volume de injeção, volume do tubo capilar do injector até a coluna (considerar a soma dos volumes no caso da existência de uma câmara para aquecimento da fase móvel), volume do tubo capilar da coluna ao detector, volume da célula de detecção, volume da pré-coluna, filtros de linha e demais conectores. Na realidade, 
esse procedimento resulta em um cálculo para o volume total do sistema HPLC a ser percorrido pela banda cromatográfica (excetuando-se a coluna). De fato, para converter a contribuição de cada um dos volumes do sistema em sua variância correspondente, deve-se considerar uma série de fatores que envolvem, entre outros, a dinâmica do fluido e o transporte de massa do analito nesse fluido. Esses cálculos vão além do pretendido com esse artigo, porém os interessados podem encontrar algumas dessas equações na referência 18, bem como a citação de trabalhos fundamentais acerca do assunto. Uma regra geral que pode ser observada nos cálculos efetuados para os equipamentos modernos é que o valor do desvio padrão $(\sigma)$ em microlitros costuma aproximar-se desse ECV, calculado acima, dividido por um fator entre 5,8 e 6,4. Dessa forma, pode-se estimar de maneira bastante aproximada que a $\sigma_{\text {extracoluna }}^{2}$, para um sistema com $45 \mu \mathrm{L}$ de ECV calculado pelo procedimento acima, estará em torno de $55 \mu \mathrm{L}^{2}$.

Outro método consiste em medir diretamente o valor de $\sigma_{\text {extracoluna a partir de um }}^{2}$ pico obtido em um sistema cromatográfico sem coluna. O método de análise deve ser aprontado de maneira similar ao que será utilizado para uma análise cromatográfica (mesma fase móvel, mesmo analito e mesma vazão); todavia, no local da coluna, deverá ser utilizado um conector tipo união com volume morto desprezível. Outro cuidado importante é ajustar o detector para a maior taxa de aquisição possível e o seu tempo de resposta para o mais curto possível. Deve-se lembrar de não utilizar uma vazão maior do que $0,5 \mathrm{~mL} / \mathrm{min}$ caso a taxa máxima de aquisição do detector seja de $10 \mathrm{~Hz}$, ou maior do que $1,0 \mathrm{~mL} / \mathrm{min}$, caso a taxa seja de $20 \mathrm{~Hz}$ (do contrário menos do que 20 pontos poderão ser adquiridos ao longo do pico cromatográfico, prejudicando a estimativa). A seguir, após o sistema estar estabilizado, injeta-se uma solução contendo um dos analitos de interesse, alternativamente pode ser injetada uma solução de uracila ou $0,1 \%$ $\left(\mathrm{v} . \mathrm{v}^{-1}\right)$ de acetona na fase móvel. O volume a ser injetado faz parte da estimativa da dispersão a ser calculada, portanto, variações nesse volume afetam o valor obtido. Recomenda-se injetar o volume definido pelo método em avaliação, caso a estimativa seja para essas condições, ou o menor volume possível de ser injetado pelo amostrador, caso a contribuição do volume injetado queira ser negligenciada. Finalmente, a partir do pico registrado no cromatograma dessa injeção, deve-se calcular o valor de oextracoluna tangenciando-se o pico até a linha de base (largura das tangentes na linha de base $=4 \sigma$ ), ou medindo-se a largura dele a meia altura (largura do pico a meia altura $=2,355 \sigma$ ). Esse valor de $\sigma$, se calculado em unidades de tempo, deve ter seu valor multiplicado pela vazão utilizada na coluna, de maneira a encontrar o valor de oextracoluna em unidades volumétricas e assim calcular o valor de $\sigma_{\text {extracoluna }}^{2}$ em $\mu \mathrm{L}^{2}$.

Outra forma de estimar a $\sigma_{\text {extracoluna }}^{2}$ válida para sistemas em que essa variância não seja significativa sobre o alargamento de picos cromatográficos. Nesse caso, deve-se proceder com a injeção de uma solução composta por diferentes padrões (uracila (marcador de volume morto), álcool benzílico, benzonitrila, nitrobenzeno, 4-cloro-1-nitrobenzeno, tolueno e anisol já foram usados com sucesso) no sistema HPLC, sob as mesmas condições. Geralmente a escolha de uracila e mais três ou quatro compostos é suficiente. Condição adequada para uma coluna de $150 \times 4,6 \mathrm{~mm}$ utiliza uma vazão de 1,2 mL/min e fase móvel com força suficiente para eluir os padrões com um fator de retenção entre 1 e 5. A seguir, injeta-se um volume adequado da solução dos padrões (o volume definido pelo método em avaliação, 
caso a estimativa seja para essas condições, ou o menor volume possível de ser injetado pelo amostrador, caso a contribuição do volume injetado queira ser negligenciada). A partir do cromatograma obtido, calcula-se então o tempo de retenção e a largura de cada pico a meia altura. Esses valores, se multiplicados pela vazão, serão convertidos às respectivas medidas volumétricas. Finalmente, faz-se um gráfico plotando-se a variância do pico $\left(\sigma^{2}\right)$ (obtida ao dividir-se a largura volumétrica a meia altura por 2,355 e elevar o valor ao quadrado) em função do seu respectivo volume de retenção ao quadrado $\left(V_{R}^{2}\right)$, ambos com as mesmas unidades volumétricas ao quadrado (geralmente $\mu \mathrm{L}^{2}$ ). Dessa forma, o intercepto da reta de regressão linear desse gráfico equivalerá ao valor de $\sigma_{\text {extracoluna }}^{2}$ e a inclinação da reta a $1 / N$. A Figura 7 apresenta a maneira gráfica de se estimar o valor de $\sigma_{\text {extracoluna; }}^{2}$ no exemplo dado no gráfico, o valor obtido pelo intercepto do gráfico equivale a $45,7 \mu \mathrm{L}^{2}$.

As referências de 18 a 20 apresentam mais detalhes sobre a estimativa do ECV ou da $\sigma_{\text {extracoluna }}^{2}$ existente em um sistema HPLC.

\section{Como ajustar as configurações de um HPLC convencional}

As discussões acima deixam claro que um equipamento HPLC convencional não adequadamente configurado provavelmente prejudicará o melhor desempenho de colunas com altíssima eficiência. É importante reforçar que, quanto maior for o ECV, mais eficiente for a coluna, menor for o seu diâmetro interno, e menos retidos forem os analitos, mais comprometedores serão os efeitos do alargamento extracoluna. Outros fatores, tais quais, temperatura de análise, viscosidade da fase móvel, coeficiente de difusão do analito na fase móvel, também afetam esse alargamento, todavia ultrapassam o escopo desse artigo.

Uma forma bastante simples de verificar na prática se a sua coluna está sendo afetada pelo excesso de alargamento causado pelo sistema é fazer a comparação entre a eficiência de um pico pouco retido $(k<2)$ e a de outro relativamente mais retido $(k>4)$. Uma perda superior a $20 \%$ na eficiência do primeiro pico em relação ao segundo é um forte indício de que fontes externas à coluna estejam prejudicando a eficiência global da análise (Figura 8).

Os procedimentos de otimização de um HPLC convencional, abaixo apresentados, seguirão uma ordenação de acordo com o grau de facilidade para serem implementados. É importante destacar que alguns equipamentos mais recentes já possuem alguns dos causadores de dispersão, apresentados a seguir, bastante reduzidos, portanto algumas das etapas a serem discutidas podem não surtir efeitos ou serem desnecessárias.

\subsection{Configurações de aquisição de dados do detector}

Esse primeiro aspecto a ser considerado não está relacionado com o ECV do sistema, mas sim com as condições de detecção do pico cromatográfico. Conforme foi apresentado, idealmente um pico cromatográfico deve ter, ao menos, 20 pontos de aquisição ao longo de sua extensão. Para isso, uma taxa mínima de aquisição é necessária. Valores muito baixos deformam o pico, tornando-o alargado e prejudicando a sua integração; por outro lado, uma frequência de aquisição desnecessariamente alta acarreta maior ruído da linha de base. Um detector UV convencional costuma ter uma taxa máxima de aquisição da ordem de 10 a $20 \mathrm{~Hz}$, tais taxas são suficientes para adquirir um mínimo aceitável de pontos ao longo de picos com largura a meia altura de 0,69 e 0,34 segundos, respectivamente. 


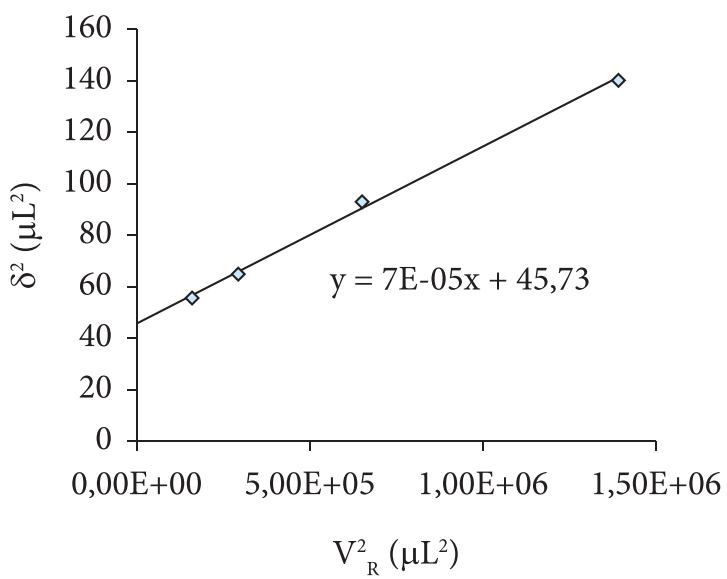

Figura 7 Gráfico da variância em função do volume de retenção ao quadrado para uma série de compostos (uracila, álcool benzílico, benzonitrila e anisol), demonstrando a estimativa do $\sigma_{\text {extracoluna }}^{2}$ partir do intercepto da reta e do número de pratos $(\mathrm{N})$ a partir do inverso da inclinação.

Coluna HALO C18, $150 \mathrm{~mm} \times 4,6 \mathrm{~mm}$, fused-core

Agilent 1100 com configuração padrão $($ ECV calculado $=36 \mu \mathrm{L})$

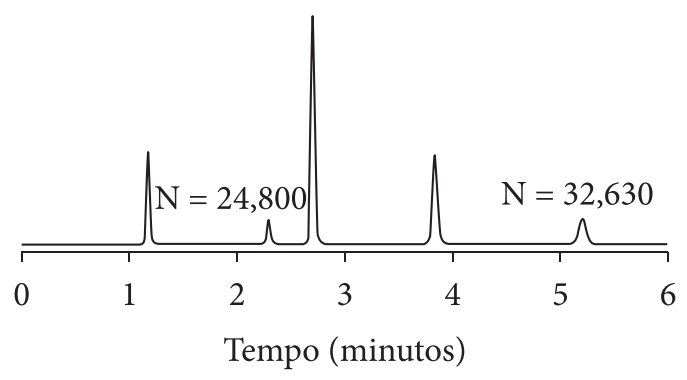

Agilent 1100 com configuração modificada $(\mathrm{ECV}$ calculado $=12 \mu \mathrm{L})$

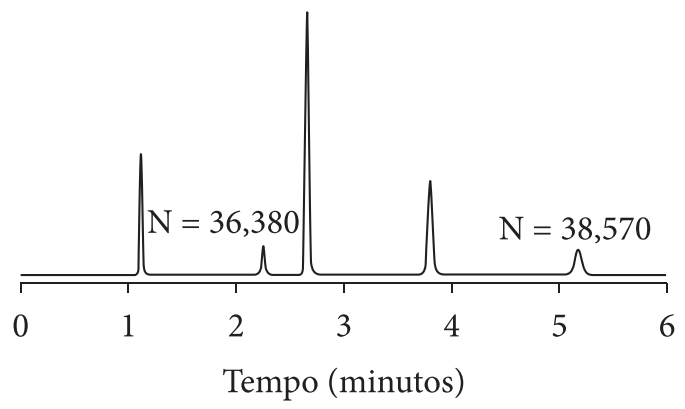

Figura 8 Demonstração da perda de eficiência de um pico pouco retido em relação a outro mais retido em um sistema HPLC convencional e em outro com configuração otimizada. Adaptada da referência 21.
Outros tipos de detectores também necessitam dos mesmos requisitos, haja vista a demanda, por exemplo, por espectrômetros de massa com altas taxas de aquisição de dados (baixos valores de dwell time e duty cycle) para serem acoplados a sistemas UHPLC.

Outro aspecto importante são os filtros de ruído utilizados pelos detectores e softwares dos equipamentos. Conforme já foi mencionado, quanto mais longo for o tempo do filtro de ruído, maior a eliminação do ruído; todavia, um tempo demasiadamente longo em proporção à largura do pico leva à sua deformação. Nesse ponto, é importante recorrer ao manual do equipamento para saber as possibilidades de filtros de ruído a serem aplicadas e a sua relação com a constante de tempo do detector. Alguns equipamentos apresentam um tempo de resposta que está relacionado à constante de tempo por um determinado fator. No caso da espectrometria de massas, diversos filtros matemáticos podem ser utilizados para o alisamento (smoothing) dos picos cromatográficos; contudo eles devem ser usados com parcimônia para não causar excessivo alargamento. Uma equação simples para estimar o tempo de resposta máximo para um determinado pico é mostrada a seguir ${ }^{22}$ :

$$
\tau=\theta \times \frac{t_{R}}{\sqrt{N}}
$$

em que, $\tau$ é a constante de tempo e $\theta^{2}$, o grau de alargamento aceitável para o pico. Por exemplo $\theta=0,3$ para um alargamento aceitável de $9 \%$.

No entanto, como a relação entre o tempo de resposta do detector/software e a constante de tempo pode não ser conhecida, o manual do equipamento é uma fonte importante de consulta, pois deverá conter uma relação entre o tempo de resposta máximo para picos com uma determinada largura mínima, de maneira a não deteriorar a eficiência desses picos em um percentual valor determinado. Alternativamente, um ajuste empírico da taxa de amostragem e 
principalmente do fator de resposta pode ser conseguido rapidamente comparando-se as eficiências obtidas para cromatogramas adquiridos em diferentes condições. O cromatograma apresentado na Figura 9 e os respectivos dados compilados na Tabela 1 ilustram esse procedimento.

\subsection{Volume dos tubos conectores e ajuste das conexões}

O ajuste dos volumes dos tubos conectores do sistema pode ser um pouco trabalhoso. Todavia, um usuário cuidadoso pode fazer a maior parte desses ajustes sem a necessidade de

Tabela 1 Influência das condições de aquisição de um detector UV/Vis sobre a eficiência cromatográfica exibida pelos picos.

\begin{tabular}{cccccc}
\hline \multirow{2}{*}{$\begin{array}{c}\text { Tempo de } \\
\text { resposta } \\
\text { (segundos) }\end{array}$} & $\begin{array}{c}\text { Taxa de } \\
\text { aquisição } \\
(\mathrm{Hz})\end{array}$ & Uracila & Fenol & 4-cloro-nitrobenzeno & Naftalento \\
\cline { 3 - 6 } & 0,008 minutos & $\begin{array}{c}w_{h} \\
0,011 \text { minutos }\end{array}$ & $\begin{array}{c}w_{h} \\
0,021 \text { minutos }\end{array}$ & $\begin{array}{c}w_{h} \\
\text { m,031 minutos }\end{array}$ \\
\hline 0,02 & 80 & 16.240 & 21.641 & 25.706 & 25.061 \\
0,1 & 40 & 15.514 & 22.028 & 25.705 & 25.080 \\
0,2 & 20 & 12.755 & 18.647 & 24.699 & 24.506 \\
0,5 & 10 & 6.965 & 12.658 & 21.712 & 23.872 \\
\hline
\end{tabular}

No destaque a condição que não acarreta perda significativa de eficiência para os compostos estudados.

Reproduzida com a permissão de Agilent Technologies.

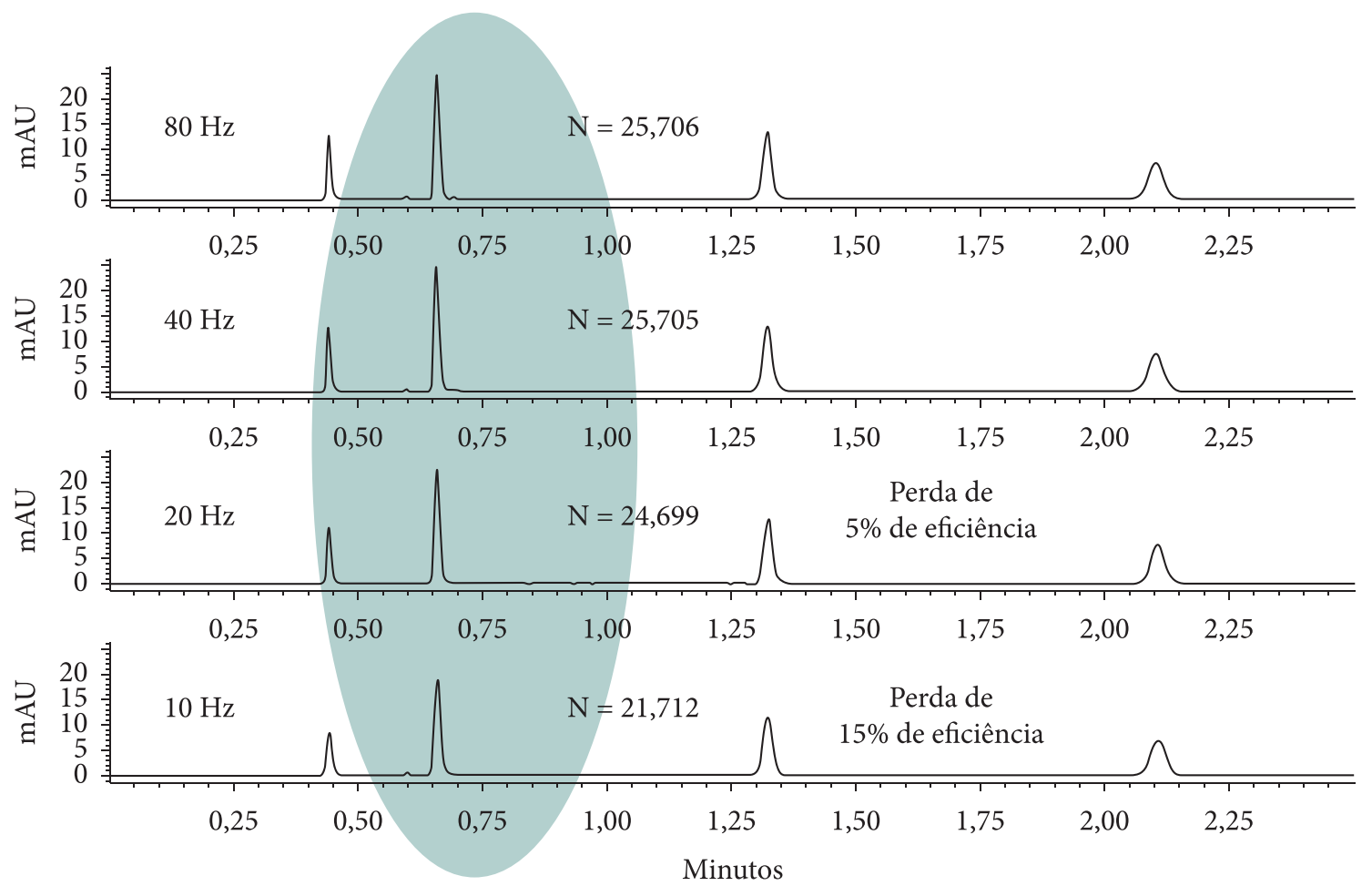

Figura 9 Comparação da influência de diferentes condições de aquisição de um detector UV/Vis sobre a eficiência cromatográfica. Dados obtidos para uma coluna Poroshell 120 EC-C18, $100 \times 4,6 \mathrm{~mm}$; "SPP 2,7 $\mu \mathrm{m}^{\text {", }}$ com fase móvel: $\mathrm{ACN}: \mathrm{H}_{2} \mathrm{O}, 60: 40\left(\mathrm{v} \cdot \mathrm{v}^{-1}\right)$, vazão de $2,0 \mathrm{~mL} / \mathrm{min}, 2 \mu \mathrm{L}$ de injeção e célula de deteç̧ão com $2 \mu \mathrm{L}$. Reproduzida com a permissão de Agilent Technologies. 
um técnico especializado, desde que tomados os cuidados que serão mencionados. Apesar de um pouco mais difícil do que a substituição da célula de detecção (a ser discutida na seção 4.4), a substituição dos tubos é mais barata; por exemplo, $3 \mathrm{~m}$ de tubo PEEK, com resistência a pressões superiores a 550 bar, podem ser adquiridos no mercado nacional por menos de $\mathrm{R} \$ 200$ reais.

Os sistemas convencionais muitas vezes estão configurados com tubos com diâmetro interno (d.i.) de $254 \mu \mathrm{m}$ (0,010"), os quais contribuem com um ECV de $0,51 \mu \mathrm{L} . \mathrm{cm}^{-1}$ de tubo. Um sistema com um total de $50 \mathrm{~cm}$ de tubos desse d.i. (algumas configurações podem ter bem mais) teria mais do que $25 \mu \mathrm{L}$ de ECV apenas por conta das tubulações.

Recomenda-se a substituição das tubulações do equipamento (todas entre o injetor e o detector) por tubos com d.i. de $127 \mu \mathrm{m}(0,005$ ") com o menor comprimento possível. Esses tubos contribuem com ECV de apenas $0,13 \mu \mathrm{L} . \mathrm{cm}^{-1}$, o qual é mais compatível com os sistemas otimizados. Não se recomendam tubos ainda mais estreitos, pois eles apresentam maior facilidade de obstruções e elevam de maneira incompatível a pressão extracoluna do equipamento. Alguns fabricantes oferecem tubos pré-cortados com as dimensões adequadas para substituir as tubulações originais do equipamento. Da mesma maneira, alguns tubos e dispositivos do amostrador automático podem ser reconfigurados para menores volumes (recomenda-se consulta ao manual do equipamento). Como exemplo, pode-se citar a possibilidade de troca do assento da agulha de injeção de alguns injetores automáticos, a qual traz consigo um tubo conector que pode ter o seu volume reduzido. Em caso de dúvidas, o representante de vendas ou técnico responsável pelo equipamento pode ser consultado.
Além dos volumes dos tubos, a qualidade da conexão entre eles também é importante. Deve-se garantir que a posição do tubo no interior da conexão esteja bem ajustada, de maneira a não restar um espaço vazio, funcionando como "câmara de mistura". No caso da substituição da tubulação por tubos de PEEK comprados em "batelada" (não cortados de fábrica no comprimento adequado), deve-se utilizar cortador de tubos apropriado, bem como garantir que os cortes sejam perfeitamente perpendiculares. Outra fonte de problemas são as conexões incompatíveis entre si. Apesar de algumas conexões terem comportamento quase universal, deve-se atentar à escolha correta dos conectores e anilhas utilizados em válvulas, colunas e demais dispositivos do equipamento. A Figura 10 ilustra algumas possíveis incompatibilidades entre conectores de diferentes marcas ou erros no ajuste da anilha; enquanto a Figura 11 demonstra o efeito desse erro de conexão sobre o cromatograma. Mais detalhes sobre problemas com conexões são discutidos na referência 23.

Como última observação sobre esse assunto, apesar de os tubos de PEEK recomendados suportarem pressões superiores a 500 bar, alguns sistemas cromatográficos podem requerer tubos mais resistentes. Uma alternativa simples aos tubos de PEEK são os denominados PEEKsil’, os quais são tubos de sílica fundida revestidos externamente por PEEK. Esses tubos possuem resistência superior a 680 bar e são vendidos em diversos comprimentos e diâmetros internos; por exemplo, um pacote com 5 tubos de $200 \mathrm{~mm}$ e $100 \mu \mathrm{m}$ de d.i. pode ser adquirido no mercado brasileiro por aproximadamente 70 dólares (excluídas taxas locais de importação e frete). As conexões e anilhas de PEEK são uma alternativa muito usual às respectivas de aço inoxidável; todavia, geralmente, são recomendadas para pressões de até 400 bar. 
Anilha não se ajusta

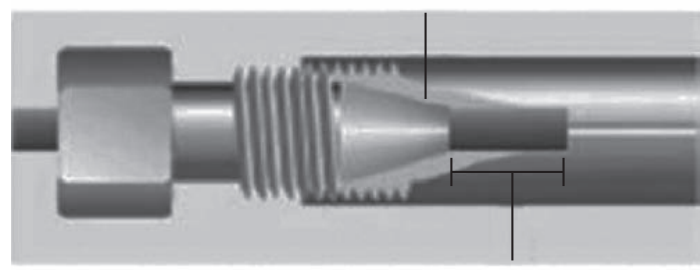

Comprimento muito longo

"Causa vazamento"

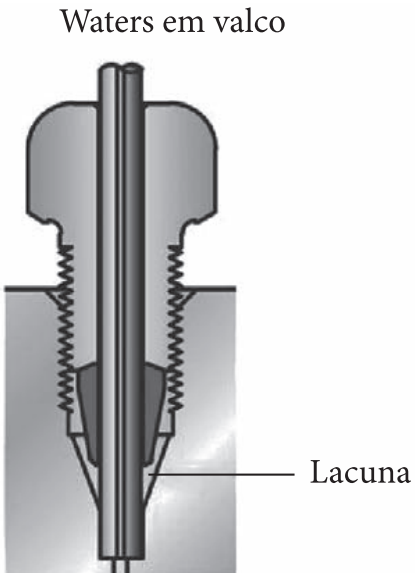

Valco em waters

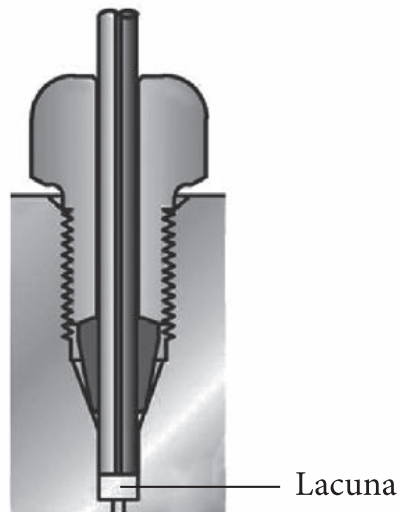

(b)
Câmara de mistura

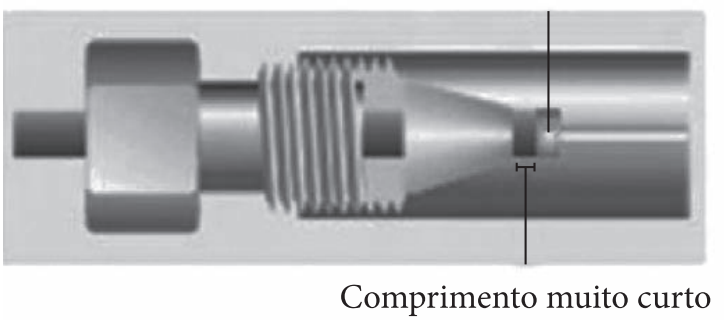

"Forma uma câmara de mistura"

(a)

Figura 10 a) Erros no ajuste da posição da anilha de vedação. b) Exemplo da incompatibilidade entre conexões de diferentes fabricantes. Adaptado de Upchurch Scientific.

No caso da necessidade de lidar com pressões mais altas, existem conexões fabricadas com o polímero policetona $(\mathrm{PK})$, as quais usualmente resistem a pressões superiores a 800 bar e temperaturas de até $200^{\circ} \mathrm{C}$; adicionalmente, tal qual a maioria das conexões de PEEK, elas dispensam a utilização de chaves conectoras (Finger Tight Fittings).

\subsection{Injeção da amostra}

A injeção da amostra é crítica mesmo nos casos de análises por HPLC convencional. Já se mencionou em artigo anterior dessa seção que o excesso de volume injetado ou a injeção com solvente incompatível leva a distorções e alargamentos dos picos ${ }^{24}$. No caso de sistemas com colunas mais eficientes, a introdução da amostra torna-se mais crítica. A injeção de um volume de $20 \mu \mathrm{L}$ de amostra deve contribuir sozinha com uma variância maior do que $30 \mu \mathrm{L}^{2[18]}$. Uma regra geral considera como volume máximo de injeção $15 \%$ do volume de um pico obtido sob condições ideais. Todavia, esse cálculo pode ser excessivamente permissivo em alguns casos. Para um pico ideal com variância de $60 \mu \mathrm{L}^{2}$, tal volume de injeção corresponderia a aproximadamente 4,6 $\mu \mathrm{L}$ e sozinho corresponderia a uma variância superior a $1,8 \mu \mathrm{L}^{2}$. Ademais, como outras fontes de alargamento para a banda estão presentes no injetor do sistema, os volumes ótimos injetados em colunas de mais alta eficiência muitas vezes não superam os $3 \mu \mathrm{L}$ (exceto se for utilizada etapa de focalização ou compressão 

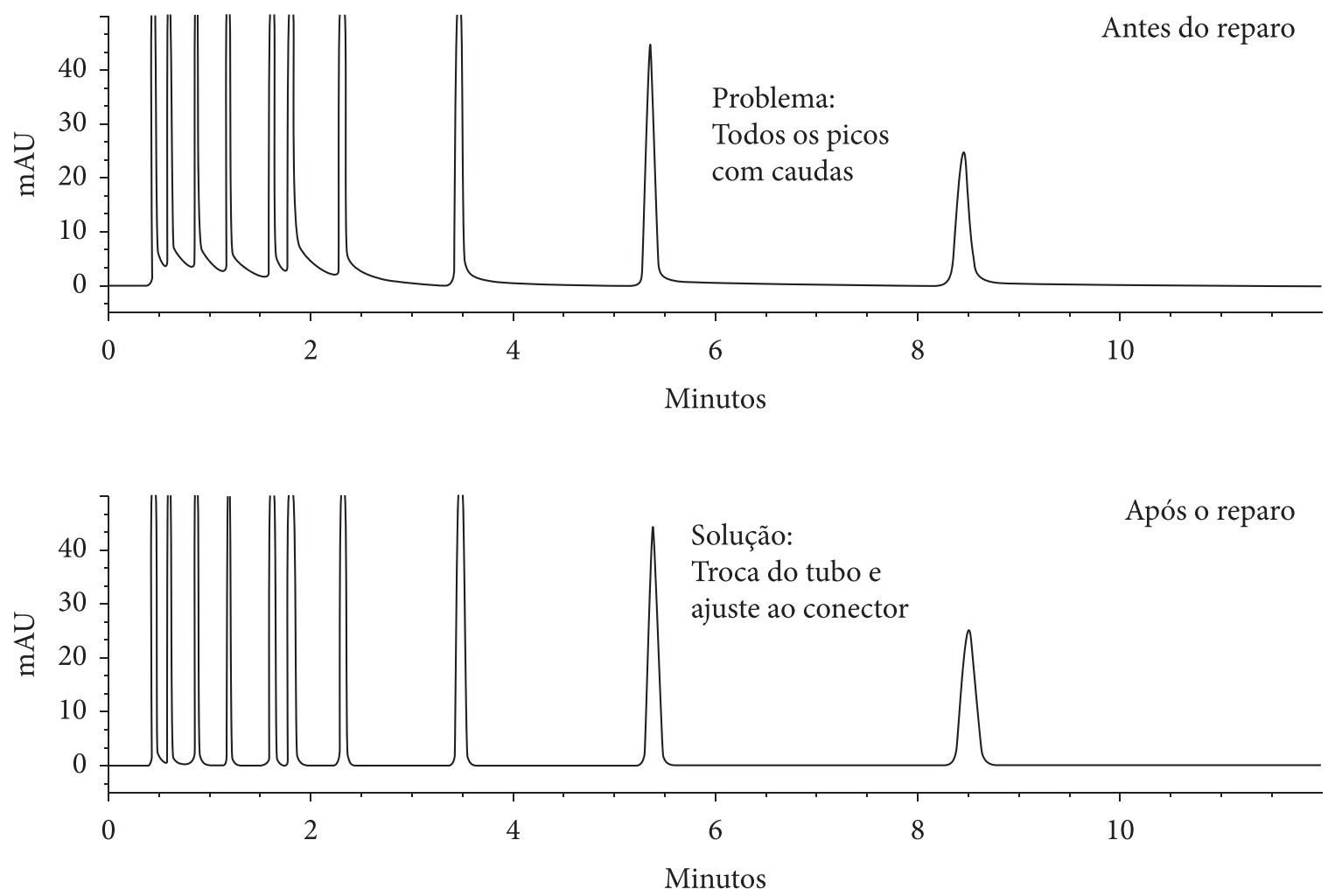

Figura 11 Alargamento e assimetria de picos causada por lacuna entre o tubo e a base da conexão. Reproduzida com a permissão de Agilent Technologies.

da banda). Uma maneira simples de observar o efeito do volume de injeção seria injetar um volume correspondente a $15 \%$ do volume calculado para um pico ideal (aproximadamente $5 \mu \mathrm{L}$ para uma coluna $50 \times 4,6 \mathrm{~mm}$ ) e, então, proceder com injeções comparativas, reduzindo-se gradativamente o volume injetado. Nesse ponto, convém relembrar que, dependendo do tipo de amostrador automático ou injetor manual utilizado, limitações quanto aos volumes mínimos permitidos e precisões obtidas podem estar presentes. De maneira geral, no caso de injeções manuais, convém ser utilizado o modo de preenchimento total da alça, testando-se alças de reduzidos volumes nominais até encontrar o maior volume que não forneça contribuição significativa ao alargamento dos picos. No caso de amostradores automáticos, primeiramente o tipo de procedimento de amostragem rea- lizado pelo equipamento deve ser verificado, bem como os menores volumes que podem ser introduzidos com precisão (em alguns modelos, esse volume é inerente à alça de amostragem utilizada, e a sua substituição pode ser requerida para a injeção de menores volumes). Dessa forma, dada a versatilidade desses amostradores automáticos para a injeção de volumes variados dentro de um intervalo aceitável, o maior volume possível deve ser ajustado de maneira a não contribuir com o alargamento dos picos. Finalmente, é importante mencionar que as injeções dos maiores volumes possíveis de amostra somente se fazem necessárias quando amostras contendo analitos ao nível de traços são analisadas. Em outras situações, os volumes podem ser reduzidos sem grandes preocupações, desde que respeitadas as limitações de precisão do equipamento. 
Estratégias interessantes para permitir a injeção de volumes mais altos de amostra baseiam-se na focalização ou compressão dos picos dos compostos menos retidos. A focalização consiste em utilizar, na solução da amostra, um solvente mais fraco do que aquele utilizado como fase móvel no início da corrida cromatográfica. A compressão depende da possibilidade de programação do sistema de injeção utilizado e consiste em um volume de água (adicionado por uma programação de injeção em multietapas do injetor) a ser eluído logo em seguida à banda de injeção da amostra. A Figura 12 ilustra o efeito da injeção de 1,0 $\mu \mathrm{L}$ de amostra na presença e ausência de um volume de $10 \mu \mathrm{L}$ de água para gerar compressão das bandas ${ }^{25}$. Aumentos de $8 \%$ na resolução entre os picos 2-3 e 3-4 foram observados com o procedimento de compressão. Um cuidado especial deve ser observado para compostos com pequena retenção (geralmente $k<0,3$ ), uma vez que, dependendo das características do analito e do solvente da fase móvel, a mistura entre o volume adicional de água e a banda correspondente ao pico do composto pode gerar distorções no pico desses compostos.

Até o momento, as discussões foram baseadas em análises isocráticas, as quais dependem de uma adequada introdução da amostra para evitar o alargamento demasiado da banda cromatográfica. Por sua vez, as análises com gradiente promovem naturalmente um processo de compressão da banda para a maioria dos compostos. Dessa forma, análises no modo gradiente são menos exigentes com o excesso de volume que antecede a coluna analítica, desde que a proporção inicial do gradiente seja fraca o suficiente para evitar uma rápida eluição dos primeiros analitos da amostra. Obviamente, os analitos muito pouco retidos devem receber especial atenção. Assim, qualquer sinal de alargamento em relação aos picos mais retidos é um indício

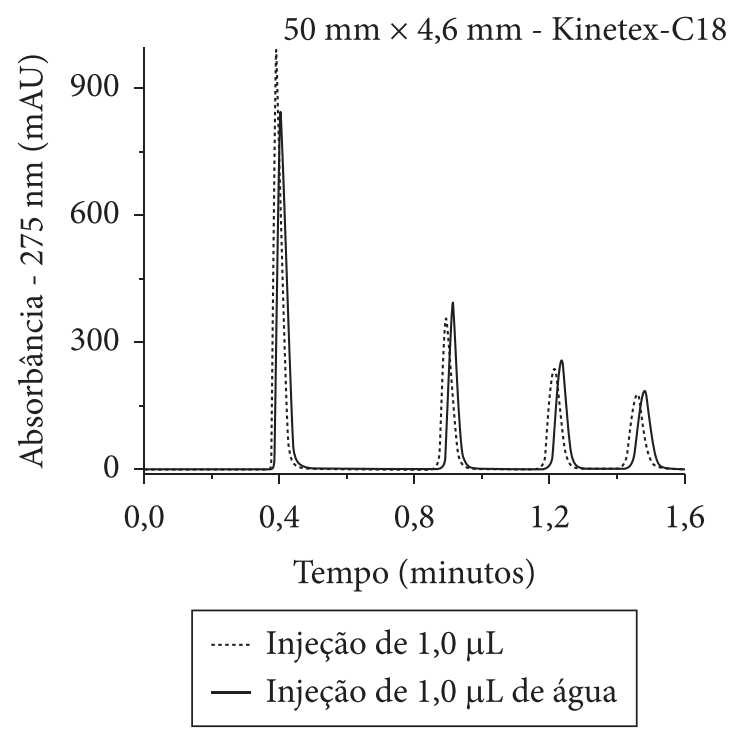

Figura 12 Avaliação da influência de um volume adicional de água para compressão das bandas cromatográficas. Picos em ordem de elvição: uracila, 2-etilfenol, 4-propilfenol, e 4-terc-butilfenol. Fase móvel: $\mathrm{MeOH}: \mathrm{H}_{2} \mathrm{O}, 65: 35\left(\mathrm{v} \cdot \mathrm{v}^{-1}\right)$ a $1,25 \mathrm{~mL} / \mathrm{min}$. Republicado a partir da referência 25 , com permissão da Elsevier.

de que o excesso de volume não está sendo totalmente suprimido pela focalização e compressão da banda desses compostos.

\subsection{Volume da célula do detector}

Em adição às características de aquisição dos dados já mencionadas, o próprio volume da célula de detecção do equipamento pode causar alargamentos desnecessários. Um detector típico de HPLC convencional possui uma célula com volume de $10 \mu \mathrm{L}$ ou pouco maior. Dependendo da eficiência da coluna e da retenção do composto, células denominadas semimicro são mais recomendadas. Por causa da necessidade de aquisição de uma nova célula, esse procedimento não foi listado entre os primeiros a serem tomados na otimização do sistema. O custo de uma célula desse tipo é de aproximadamente $\$ 1.700$ dólares (sem taxas de importação), e a substituição da célula convencional do equipamento pode ser 
realizada em poucos minutos. Talvez com o uso de uma coluna com $4,6 \mathrm{~mm}$ de diâmetro interno e 100 ou $150 \mathrm{~mm}$ de comprimento, a perda de eficiência para compostos relativamente mais retidos não seja muito grande; todavia colunas mais curtas e estreitas, bem como compostos pouco retidos, tendem a ser mais afetados pelo excesso de volume. A Figura 13 mostra o efeito desse volume sobre uma coluna $100 \times 3,0 \mathrm{~mm}$. Observa-se que uma célula semi-micro com $5 \mu \mathrm{L}$ é suficiente, enquanto uma célula convencional afeta o desempenho em mais do quase $12,5 \%$. Para colunas com diâmetro menor, por exemplo, 2,1 mm, células micro com volume de 2 $\mu \mathrm{L}$ ou ainda menores podem ser necessárias. É importante realizar a avaliação do efeito desse volume após ajustar adequadamente a taxa de aquisição e o tempo de resposta do detector. A Figura 13 deixa claro que o uso inadequado das

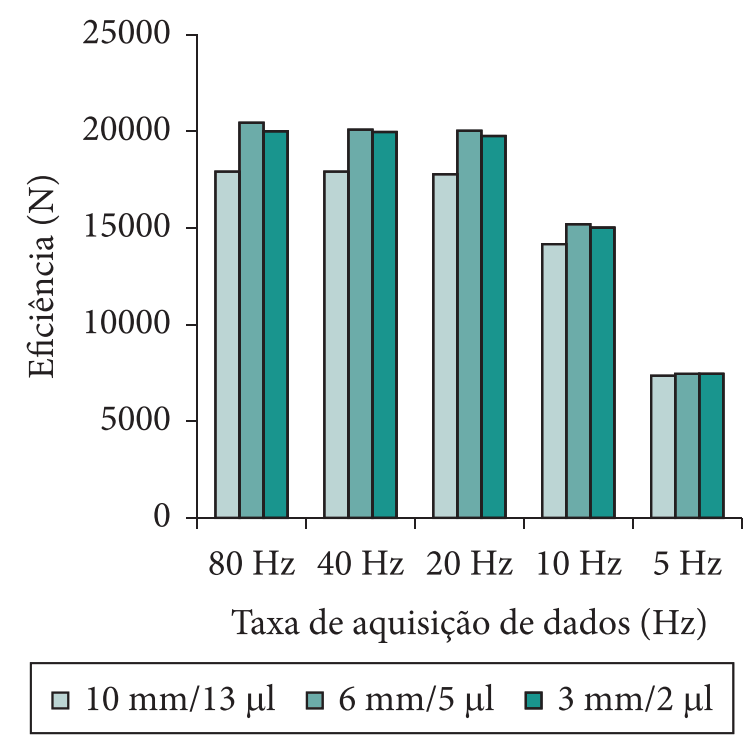

Figura 13 Avaliação do efeito do volume da célula de detecção e da taxa de aquisição do detector sobre a eficiência. Células avaliadas (caminho óptico / volume): $10 \mathrm{~mm} / 13 \mu \mathrm{L}, 6 \mathrm{~mm} / 5 \mu \mathrm{L}$, e $3 \mathrm{~mm} / 2 \mu \mathrm{L}$. Dados obtidos para uma coluna Poroshell 120 EC-C18, $100 \times 3,0$ mm; "SPP 2,7 $\mu \mathrm{m}^{\prime}$, com fase móvel: $A C N: \mathrm{H}_{2} \mathrm{O}, 60: 40\left(\mathrm{v} \cdot \mathrm{v}^{-1}\right)$, vazão de $0,8 \mathrm{~mL} / \mathrm{min}$, $2 \mu \mathrm{L}$ de injeção. Reproduzida com a permissão de Agilent Technologies. condições de aquisição não deixa perceptível a perda de eficiência causada pelo excesso de volume da célula.

\section{Considerações finais}

Em síntese, os passos sugeridos para a otimização de um sistema convencional de maneira a minimizar os efeitos extracoluna sobre o alargamento do pico cromatográfico são:

1. Ajustar as condições de detecção. Um bom valor inicial sugerido seria uma taxa de aquisição de, ao menos, $10 \mathrm{~Hz}$ e tempo de resposta do detector inferior a 0,3 segundos.

2. Substituir a tubulação do equipamento por tubos com d.i. de $127 \mu \mathrm{m}$ e menor comprimento possível e assegurar que as conexões estão bem feitas.

3. Adequar o volume de injeção da amostra e/ou utilizar uma estratégia de focalização/ compressão das bandas cromatográficas.

4. Utilizar uma célula de detecção com volume compatível ( $5 \mu \mathrm{L}$ para colunas com $4,6 \mathrm{~mm}$ d.i. ou $\leq 3 \mu \mathrm{L}$ para $2,1 \mathrm{~mm}$ d.i.).

As sugestões de otimização apresentadas neste artigo visam a extrair o máximo de eficiência de um sistema HPLC convencional. Para isso, busca-se minimizar todas as fontes de alargamento dos picos cromatográficos, de maneira que colunas curtas e de altíssima eficiência possam ser utilizadas com as mais altas vazões permitidas pelas limitações de pressão do equipamento, possibilitando análises ultrarápidas. É óbvio que nem todos os usuários têm necessidades de eficiências tão altas, de tal forma que um equipamento "não otimizado" pode ser plenamente satisfatório para alguns. Ademais, um usuário com limitações de tempo ou recursos pode implementar apenas parte das etapas de otimização sugeridas, até o ponto de se atingir os valores de eficiência demandados. 


\section{Agradecimentos}

Ao Dr. Ron Majors por, gentilmente, ceder, sob a permissão de Agilent Technologies, algumas das figuras utilizadas. (http://www.chem.agilent. com/en-US/Products/columns-supplies/lc-lc-mscolumns/poroshell/Pages/poroshell120video.aspx).

\section{Referências}

1 Guillarme D, Ruta J, Rudaz S, Veuthey JL. New trends in fast and high-resolution liquid chromatography: a critical comparison of existing approaches. Analytical and Bioanalytical Chemistry 2010; 397:1069.

2 Brice RW, Zhang X, Colón LA. Fused-Core, Sub-2 $\mu \mathrm{m}$ packings, and monolithic HPLC columns: a comparative evaluation. Journal of Separation Science 2009; 32:2723.

3 Lestremau F, De Villiers A, Lynen F, Cooper A, Szucs $\mathrm{R}$, Sandra P. High efficiency liquid chromatography on conventional columns and instrumentation by using temperature as a variable: Kinetic plots and experimental verification. Journal of Chromatography A 2007; 1138:120.

4 Hartonen K, Riekkola ML. Liquid chromatography at elevated temperatures with pure water as the mobile phase. Trends in Analytical Chemistry 2008; 27:1.

5 Majors RE, Carr PW. Glossary of HPLC and LC separation terms. LCGC North America 2008; 26:19.

6 Nguyen DTT, Guillarme D, Heinisch S, Barrioulet MP, Rocca JL, Rudaz S et al. High throughput liquid chromatography withsub-2um particles at high pressure and high temperature. Journal of Chromatography A 2007; 1167:76.

7 Salisbury JJ. Fused-core particles: a practical alternative to sub-2 micron particles. Journal of Chromatographic Science 2008; 46:883.

8 Halász I, Horváth C. Micro Beads coated with a porous thin layer as column packing in gas chromatography. Some properties of graphitized carbon black as the stationary phase. Analytical Chemistry 1964; 36:1178.

9 Gritti F, Leonardis I, Abia J, Guiochon G. Physical properties and structure of fine core-shell particles used as packing materials for chromatography: relationships between particle characteristics and column performance. Journal of Chromatography A 2010; 1217:3819.

10 Abrahim A, Al-Sayah M, Skrdla P, Bereznitski Y, Chen Y, Wu N. Practical comparison of $2.7 \mu \mathrm{m}$ fused-core silica particles and porous sub- $2 \mu \mathrm{m}$ particles for fast separations in pharmaceutical process development. Journal of Pharmaceutical and Biomedical Analysis 2010; 51:131.

11 Fekete S, Ganzler K, Fekete J. Efficiency of the new sub-2 $\mu \mathrm{m}$ core-shell (Kinetex ${ }^{\mathrm{Tn}}$ ) column in practice, applied for small and large molecule separation. Journal of Pharmaceutical and Biomedical Analysis $2011 ; 54: 482$.

12 McCalley DV. Instrumental considerations for the effective operation of short, highly efficient fusedcore columns. Investigation of performance at high flow rates and elevated temperatures. Journal of Chromatography A 2010; 1217:4561.

13 Santos-Neto AJ. Problemas com o formato dos picos em cromatografia líquida - parte 2. Scientia Chromatographica 2009; 1(4):55.

14 Santos-Neto AJ. Uma visão técnica para a compreensão e resolução de problemas em sistemas de cromatografia líquida. Scientia Chromatographica 2009; 1(2):83.

15 Snyder LR, Kirkland JJ, Dolan JW. Introduction to modern liquid chromatography. $3^{\text {rd }}$ ed. Hoboken: Wiley; 2009.

16 Dolan JW. Autosamplers, Part I - Design and Features. LCGC North America 2001; 14(5):276.

17 Dolan JW. Autosamplers, Part II - Problems and Solutions. LCGC North America 2001; 14(6):276.

18 Fountain KJ, Neue UD, Grumbach ES, Diehl DM. Effects of extra-column band spreading, liquid chromatography system operating pressure, and column temperature on the performance of sub-2microm porous particles. Journal of Chromatography A 2009, 1216:5979.

19 Mac-Mod Analytical Inc. Technical report LC507. How to measure and reduce HPLC equipment extra column volume [cited 2010 nov.]. Available from: http://www. mac-mod.com/pdf/MMA084-ReduceECV_MM_ Singles.pdf.

20 Rehman M, Evans K, Handley A, Massey P. Tests for liquid chromatographs. Chromatographia 1987; 24:492. 
21 Mac-Mod Analytical Inc. Technical report LC500. Quick tips for converting conventional reversed-phase HPLC separations to ultra-fast separations [cited 2010 nov.]. Available from: http://www.mac-mod.com/pdf/ MMA084-ReduceECV_MM_Singles.pdf.

22 Meyer VR. High-performance liquid chromatographic theory for the practitioner. J. Chromatogr. 1985; 334:197.

23 Mac-Mod Analytical Inc. Technical report A. troubleshooting guide to plumbing problems in
HPLC [cited 2010 nov]. Available form: http://www. mac-mod.com/pdf/08_PlumbingTBS.pdf.

24 Santos-Neto AJ. Problemas com o formato dos picos em cromatografia líquida - parte 1. Scientia Chromatographica 2009; 1(3):69.

25 Gritti F, Sanchez CA, Farkas T, Guiochon G. Achieving the full performance of highly efficient columns by optimizing conventional benchmark highperformance liquid chromatography instruments. Journal of Chromatography A 2010; 1217:3000. 